\title{
Alteration of cell adhesion and cell cycle properties of ES cells by an inducible dominant interfering Myb mutant
}

\author{
Naomi Iwai' ${ }^{1}$ Kenji Kitajima ${ }^{1}$, Katsuya Sakai ${ }^{1}$, Tohru Kimura ${ }^{1}$ and Toru Nakano*,1 \\ ${ }^{1}$ Department of Molecular Cell Biology, Research Institute for Microbial Diseases, Osaka University, Yamadaoka 3-1, Suita 565- \\ 0871, Osaka, Japan
}

The Myb transcription factors, c-Myb, A-Myb, and BMyb, regulate cell differentiation and/or proliferation. To investigate the role of $\mathrm{B}-\mathrm{Myb}$ in embryogenesis, we introduced an inducible dominant interfering Myb protein (MERT) into embryonic stem (ES) cells, which express B-Myb as an exclusive member of Myb family. Disruption of normal B-Myb function by the conditional activation of MERT caused a drastic morphological alteration of $E S$ cells and $G_{1}-S$ cell cycle arrest. The inhibition of B-Myb function by MERT dissociated tightly packed ES cell colonies into dispersed single cells that subsequently detached from the culture dish. Cell adhesion analyses revealed that suppression of B-Myb function reduced the adhesion with extracellular matrix proteins, such as laminin, collagen, and fibronectin. This reduction was presumably due to decreased cell surface expression of $\beta 1$ integrin. Embryoid body formation was also severely retarded by the activation of MERT. This impairment was attributed to reduced expression of $\mathrm{E}$ cadherin, which functions as a homophilic intercellular adhesion molecule. Simultaneously, blocking B-Myb function did not alter the expression of differentiation markers. Our data indicate that B-Myb plays important roles in regulating cell adhesion and cell cycle progression. These results are well consistent with the recent report on the phenotype of B-Myb null mice and show that the regulation of cell adhesion is an important BMyb function that has not yet been assumed. Oncogene (2001) 20, $1425-1434$.

Keywords: ES cells; cell adhesion; B-Myb

\section{Introduction}

Three members of the Myb transcription factor family are found in mammals: c-Myb, A-Myb, and B-Myb (Lipsick, 1996; Ness, 1999; Weston, 1998). Gene targeting experiments have revealed that all three are involved in the control of cell differentiation and cell proliferation. These three members recognize the same target DNA sequence, but their expression patterns are

*Correspondence: T Nakano

Received 31 October 2000; revised 2 January 2001; accepted 5 January 2001 quite distinct (Mucenski et al., 1991; Tanaka et al., 1999; Toscani et al., 1997). c-Myb is predominantly expressed in immature hematopoietic cells and is downregulated with the differentiation and maturation of the cells (Westin et al., 1982). The failure of definitive hematopoiesis in c-Myb targeting mice clearly demonstrated that c-Myb is a critical regulator of hematopoietic cell differentiation (Mucenski et al., 1991). A$\mathrm{Myb}$ is required for spermatogenesis and mammary gland development, as revealed by the phenotype of AMyb-null mice (Toscani et al., 1997). In contrast to the restricted expression of $\mathrm{c}-\mathrm{Myb}$ and $\mathrm{A}-\mathrm{Myb}$, B-Myb expression is much broader in both adult and embryonic tissues (Nomura et al., 1988; Sitzmann et al., 1996). Recently, it was reported that homozygous B-Myb-deficient mutant mice died on embryonic day 4.5 to 6.5 (Tanaka et al., 1999). Embryonic stem (ES) cells express B-Myb exclusively. In spite of much effort, researchers have failed to produce $\mathrm{B}-\mathrm{Myb}^{-1-} \mathrm{ES}$ cells, which suggests that B-Myb plays crucial roles in the maintenance of ES cells. At the same time, it is obviously difficult to investigate the role of B-Myb at the cellular level using a gene targeting strategy.

ES cells are derived from the inner cell mass of blastocysts (Bradley et al., 1984; Martin, 1981). ES cells possess real totipotency, like the cells in the inner cell mass, since they can differentiate into any cell lineage once re-introduced into blastocysts. ES cells can be cultured as adherent cells on a layer of embryonic fibroblasts or in culture dishes coated with gelatin (Joyner, 1993). This suggests that some cell adhesion property of the cells is important for their maintenance. Numerous gene-targeting experiments have shown that ES cells are very useful for investigating gene function during mouse ontogeny. At the same time, analyses of the cell adhesion properties of null mutant ES cells have revealed that these cells are a powerful tool for analysing the molecular mechanisms of cell adhesion. For example, E-cadherin-deficient ES cells are defective in cell aggregation, presumably because of altered cell-cell adhesion (Larue et al., 1996; Riethmacher et al., 1995). $\beta 1$ integrin-deficient ES cells have altered cell morphology, migration, and adhesion to a number of substrates (Fassler et al., 1995).

Inducible dominant interfering proteins are of immense benefit for investigating the function of 
intracellular proteins, such as transcription factors (Badiani et al., 1994; Lyon and Watson, 1996; Saitou et al., 1995; Taylor et al., 1996; White and Weston, 2000). In order to analyse the function of B-Myb in ES cells, we made use of MERT (Myb-Engrailed-estrogen receptor-tag), an inducible dominant protein that interferes with Myb. MERT consists of the DNA binding domain of c-Myb, the Drosophila Engrailed repressor domain, and a modified estrogen receptor hormone-binding domain (ER-HBD) (Taylor et al., 1996). The DNA binding domain allows the Engrailed repressor to bind specifically to the target gene sequences of Myb family members, thereby interfering with the expression of Myb-dependent genes. The modified ER-HBD can only be activated by an estrogen analog, 4-hydroxytamoxifen (4-OHT), which enables MERT to suppress Myb function in a 4-OHTdependent fashion (Littlewood et al., 1995). MERT is an inducible version of $\mathrm{Myb}$ dominant interfering proteins, and represses $\mathrm{Myb}$ activity conditionally. Consequently, MERT is a very powerful method for analysing the function of genes for which double negative mutant cells are difficult to obtain, like B-Myb (Tanaka et al., 1999).

We expected that inhibition of B-Myb function would alter some aspect of differentiation, since cMyb and A-Myb play important roles in cell differentiation in the tissues where they are expressed (Mucenski et al., 1991; Toscani et al., 1997). Although activation of MERT in undifferentiated ES cells gave rise to drastic morphological changes, no expression of differentiation markers for the three germ layers were detected. Instead, expression of cell adhesion molecules, such as $\beta 1$ integrin and E-cadherin, was significantly reduced by the activation of MERT. Our examination showed that B-Myb plays important roles in regulating cell adhesion and cell cycle progression in ES cells.

\section{Results}

\section{Inhibition of B-Myb activity by the activated MERT}

MERT represses the transcriptional activation of c$\mathrm{Myb}$ in a 4-OHT dependent manner. ERT, which is a defective version of MERT lacking the DNA binding domain of c-Myb, was used as a control (Taylor et al., 1996). It is reasonable to expect that MERT also inhibits the activity of B-Myb, since c-Myb and B-Myb have very homologous amino acid sequences and very similar consensus binding sequences (Nomura et al., 1988). At first, we confirmed that the activated MERT could inhibit the transcriptional activation by B-Myb in the context of ES cells. ES cell clones which constitutively expressed ERT or MERT were transfected by lipofection with a Myb responsive reporter gene, 6MBS-Luc, consisting of six tandem repeats of Myb responsive elements and luciferase gene (Takahashi et al., 2000). Then, the transfected ERT and MERT clones were cultured in the presence or absence of 4-

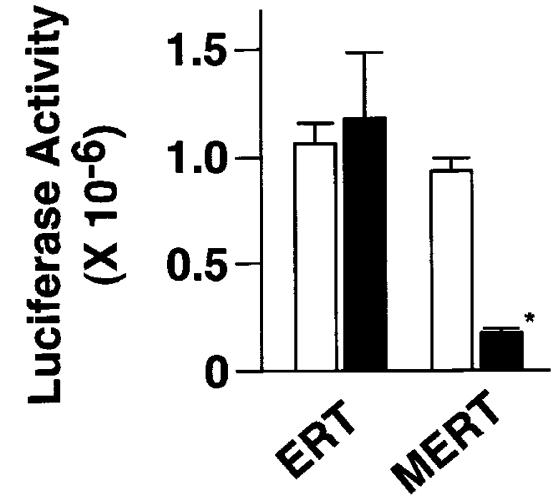

Figure 1 Inhibition of $\mathrm{B}-\mathrm{Myb}$ induced transactivation by the activated MERT ES cells constitutively expressing ERT or MERT were transfected by lipofection with a Myb responsive reporter gene, 6MBS, consisting of six tandem repeats of Myb responsive elements, tk promoter and luciferase gene. The transfected ERT and MERT clones were cultured in the presence (closed bars) or absence (open bars) of 4-OHT. Data are the mean \pm standard deviation of three samples. Statistically significant difference $(P<0.05$ by Student's $t$-test $)$ is marked with an asterisk

OHT. As shown in Figure 1, the transactivation of 6MBS was significantly reduced only in the MERT clone by the addition of 4-OHT. Since ES cells express B-Myb exclusively, it was felt that MERT should enable us to analyse the roles of B-Myb in these cells. The activation of MERT is caused by the translocation of MERT from cytoplasm to nucleus by the addition of 4-OHT (Mary Argent-Katwala and Kathy Weston, personal communication).

\section{Inhibiting Myb activity caused cell-cycle arrest}

A bicistronically EGFP-expressing plasmid (MERTIE) and a control plasmid (ERT-IE) were constructed by ligating IRES-EGFP downstream from MERT and ERT, respectively, in order to use EGFP for in vivo identification of MERT or ERT expressing ES cells. MERT-IE and ERT-IE were electroporated into D3 ES cells and stable transformants were obtained. ES cell clones transfected with MERT-IE or ERT-IE plasmids were designated as MIE and EIE, respectively. In preliminary experiments, EGFP expression of the stable clones was examined by flow cytometry. The majority of the MIE (42 out of 45) and EIE (16 out of 21) clones showed a two-peak pattern of EGFP expression. Clones MIE7, MIE24, and EIE15, which all showed the two-peak pattern (Figure 2, left panels), were used for cell growth and cell cycle analyses, in order to use the EGFP-negative cell population as an internal negative control.

First, the EGFP expression patterns of these clones were examined in the presence or absence of 4-OHT. The percentages of EGFP-expressing cells in clones MIE7 and MIE24 started to decrease around $24 \mathrm{~h}$ after the addition of 4-OHT (Figure 2, bold lines in the middle panels). This decrease continued, and highEGFP-expressing cells (R2 population in the middle 


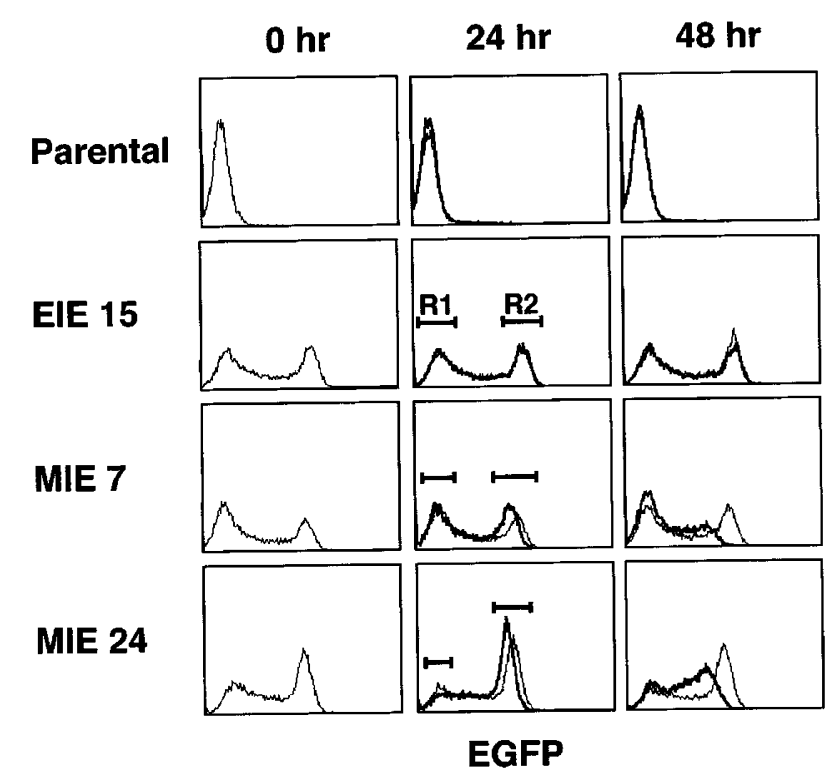

Figure 2 EGFP expression pattern of parental ES cells, clone EIE15, clone MIE7, and clone MIE24 in the presence or absence of 4-OHT. Parental ES cells, the EIE clone, and MIE clones were cultured in the absence (thin lines) or presence (bold lines) of $10^{-7} \mathrm{M}$ 4-OHT. The numbers of high-EGFP-expressing MIE cells were drastically reduced in the presence of 4-OHT. Fractions R1 and R2 were used in the experiment shown in Figure 4

panels) disappeared almost completely after $48 \mathrm{~h}$ in the presence of 4-OHT (Figure 2, right panels). In contrast, the pattern of EGFP expression of clone EIE15 was not significantly different in the presence or absence of 4-OHT (Figure 2, middle and right panels). Therefore, the presence of 4-OHT inhibited the growth of MERT clones, but not that of parental or ERT cells (Figure 3). There was no significant increase in the dead cell number of MERT clones in the presence of 4-OHT (data not shown). In addition, no significant increase in apoptosis was detected by propidium iodide staining, Hoechst 33258 staining, or DNA ladder detection, in the presence of 4-OHT (data not shown). These results suggest that the 4-OHT-induced decrease in MERTexpressing cells was due to inhibition of cell proliferation rather than cell death.

Next, we investigated whether the activated MERT brought about the cell-cycle abnormality through the inhibition of B-Myb. Clones MIE7, MIE24, EIE15, and parental ES cells were cultured in the presence or absence of 4-OHT for $24 \mathrm{~h}$. The cells of the MIE and EIE clones were sorted into $\mathrm{EGFP}^{-}$and $\mathrm{EGFP}^{+}$ populations ( $\mathrm{R} 1$ and $\mathrm{R} 2$ fractions in the middle panels of Figure 2). These sorted cells and non-sorted parental ES cells were stained with propidium iodide and their cell cycle compositions were analysed by flow cytometry. As shown in Figure 4, the 4-OHT-induced activation of MERT led to a 2-3-fold increase in the percentage of cells in $\mathrm{G}_{0}-\mathrm{G}_{1}$ phase in the $\mathrm{EGFP}^{+}$ fractions of clones MIE7 and MIE24 (from 18.1 to $44.2 \%$ and from 15.3 to $46.9 \%$, respectively). However, no significant alteration was observed in the EGFP' fractions. In contrast, 4-OHT had no significant effects on the cell cycle composition of parental ES cells or clone EIE15. These data indicate that only ES cells expressing the dominant interfering $\mathrm{Myb}$ protein were arrested in $G_{1}$ phase by activation of the protein. Thus, activation of MERT induced $\mathrm{G}_{1}-\mathrm{S}$ cell cycle arrest and subsequent cell growth retardation. Taken together with circumstantial evidence concerning the possible roles of B-Myb in cell cycle progression as discussed below, this verifies that MERT is useful for examining $\mathrm{B}-\mathrm{Myb}$ function in ES cells.

\section{Matrix adhesion properties altered by interference with Myb activity}

Unexpectedly, drastic morphological changes were observed in the 4-OHT-activated MIE clones, as shown in Figure 5. In the absence of 4-OHT, the MIE clones grew as tightly packed colonies, just like parental ES cells. However, adding 4-OHT resulted in single round cells that were detached or only loosely attached to the gelatin-coated dishes or neighboring cells (Figure 5f, h). Morphological changes in two representative MIE clones are shown: one is clone MIE7, which shows a two-peak pattern of EGFP expression (Figure 2), the other is clone MIE3, in which almost all ES cells show high expression of EGFP (data not shown). The addition of 4-OHT gave rise to similar morphological changes in these two clones, but the percentages of colonies showing these changes were significantly higher in clone MIE3 than in clone MIE7. This is probably attributable to the higher percentage of MERT-expressing ES cells in clone MIE3.

There are two explanations for this morphological change: some alteration of the state of cell differentiation or reduced cell adhesion activity. The former is unlikely, because no expression of differentiation marker genes, such as FGF-5, HNF-4, and Brachyury for the three germ layers, was detected in total cell population after the activation of MERT by 4-OHT (data not shown). Therefore, the latter possibility was examined in more depth, using clone MIE3, in which the vast majority of cells show high EGFP expression. In subsequent experiments, clone EIE12, which showed a single high peak expression of EGFP similar to clone MIE3 (data not shown), was used as a negative control.

First, the effect of activated MERT on the plating efficiency of these clones and parental ES cells was examined. One thousand ES cells were seeded onto non-coated or gelatin-coated dishes in the presence or absence of 4-OHT, and the numbers of colonies were counted 3 days later. As shown in Figure 6a, the plating efficiencies were drastically reduced in the MIE clones, in which B-Myb function was inhibited, while no effects were observed in the controls. Next, cell attachment to various extracellular matrix proteins, such as laminin, collagen, and fibronectin, was analysed. Clones MIE3 and EIE12 and parental ES cells were incubated in the presence or absence of 4OHT for $15 \mathrm{~h}$. Then, the cells were trypsinized and 
Parental

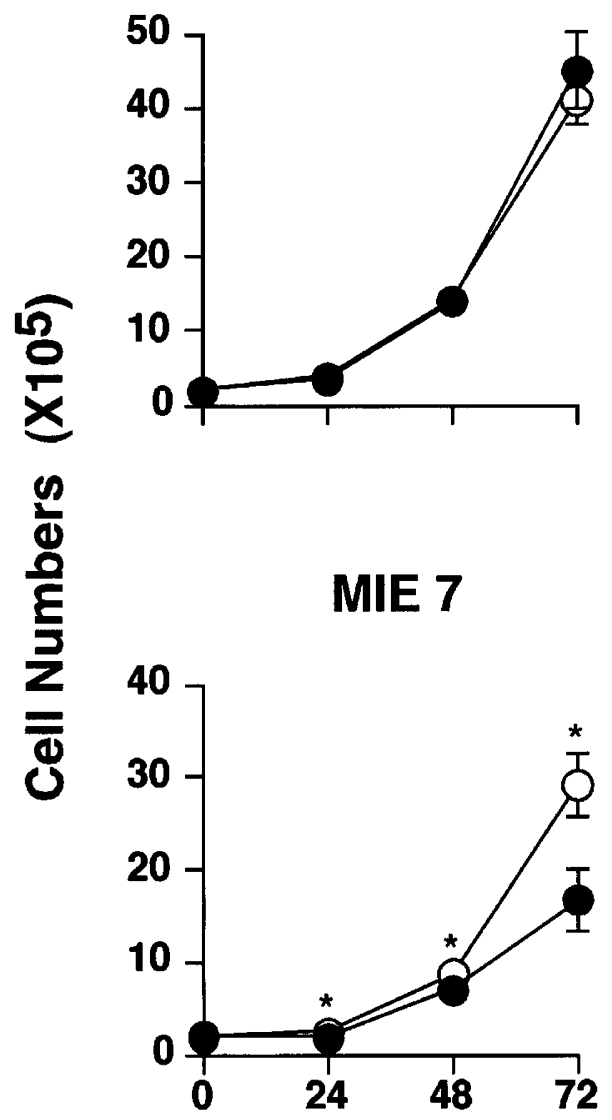

EIE 15

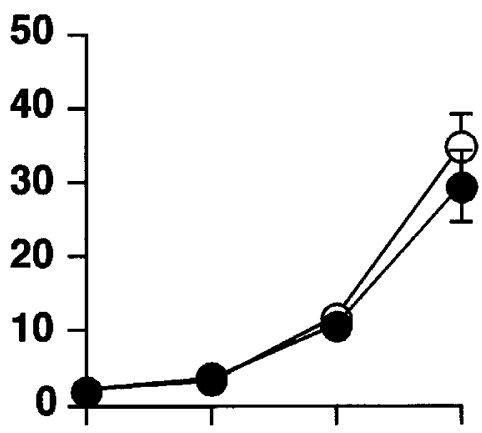

MIE 24

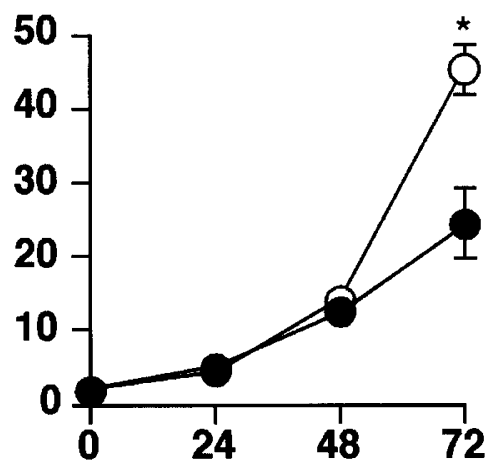

\section{Time (hr)}

Figure 3 Inhibition of B-Myb activity reduces cell numbers. Parental ES cells, the EIE clone, and MIE clones were cultured in the absence (open circles) or presence (closed circles) of 4-OHT. The numbers are shown as the mean \pm standard deviation of four samples. At the indicated time points, samples were stained with Trypan blue and counted. The presence or absence of $10^{-7} \mathrm{M} 4-$ OHT produced no significant differences in cell viability (data not shown)

plated onto tissue culture 96-well dishes coated with gelatin, laminin, collagen, or fibronectin. The adhesion of the cells was analysed $1 \mathrm{~h}$ later as described in the Materials and methods section. The MIE3 cells showed significantly reduced cell adhesion to all of the substrates in the presence of 4-OHT (Figure 6b). Essentially the same results were seen with two other MIE clones (data not shown). In contrast, the adhesion activity of parental ES cells and EIE12 cells was not decreased at all by the addition of 4-OHT.

The decreased attachment to extracellular matrix led us to investigate $\beta 1$ integrin expression in the MIE cells. When clones MIE3 and MIE7 were incubated in the presence of 4-OHT, single round cells were detached from the gelatin-coated dishes or neighboring cells after incubation for $48 \mathrm{~h}$. This non-adherent fraction showed virtually no $\beta 1$ integrin expression on the cell surfaces, while the remaining adherent fraction showed $\beta 1$ integrin expression similar to cells cultured in the absence of 4-OHT (Figure 7a). These results suggest that down-regulation of $\beta 1$ integrin expression caused by the suppression of B-Myb transactivation activity itself or subsequent reduced expression of B-Myb-regulated genes was responsible for the reduced cell adhesion activity, at least in part. However, RT-PCR analysis did not show any difference in $\beta 1$ integrin expression between the nonadherent and adherent fractions of the MIE clones (data not shown).

\section{Activated MERT affects embryoid body formation}

In order to analyse the developmental capacity of MERT cells, the embryoid body (EB) formation activity of clone MIE3 was investigated. For EB formation, $10^{4} \mathrm{ES}$ cells were cultured in methylcellulose semisolid media without LIF. 4-OHT was added 2 days after initiating the EB culture and the number of EB was counted 4 days later. Clone MIE3 produced remarkably fewer EB in the presence of 4-OHT (Figure 8a). However, some ES cell clusters that did not adhere to each other and did not produce EB remained 


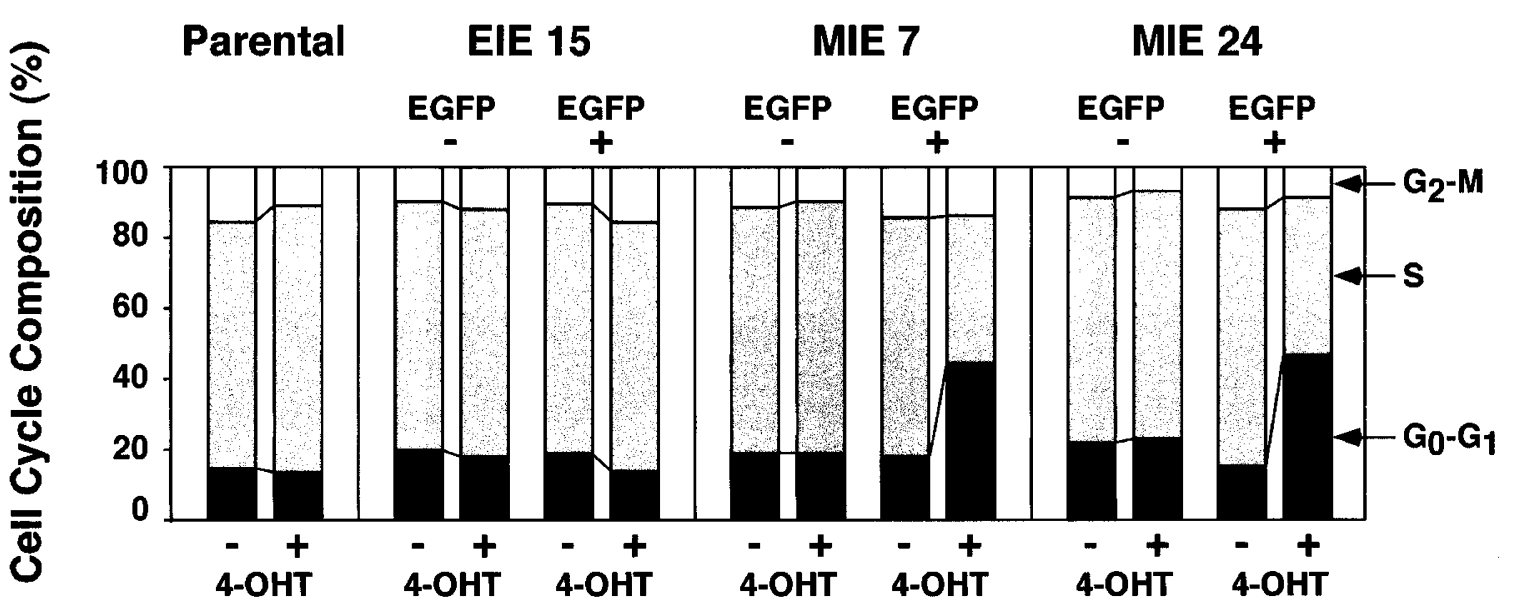

Figure 4 Inhibition of B-Myb activity causes G1-S phase cell cycle block. Parental ES cells and clones EIE15, MIE7, and MIE24 were seeded in culture medium in the presence or absence of 4-OHT as indicated for $24 \mathrm{~h}$. Fractions R1 and R2 from Figure 2 were sorted to give $\mathrm{EGFP}^{-}$and $\mathrm{EGFP}^{+}$, respectively. These sorted cells and non-sorted parental ES cells were stained with propidium iodide and their cell cycle compositions were analysed by flow cytometry. The 4-OHT-induced activation of MERT led to a $2-3-$ fold increase in the percentage of cells in $\mathrm{G}_{0}-\mathrm{G}_{1}$ phase in the $\mathrm{EGFP}^{+}$fractions of clones MIE7 and MIE24

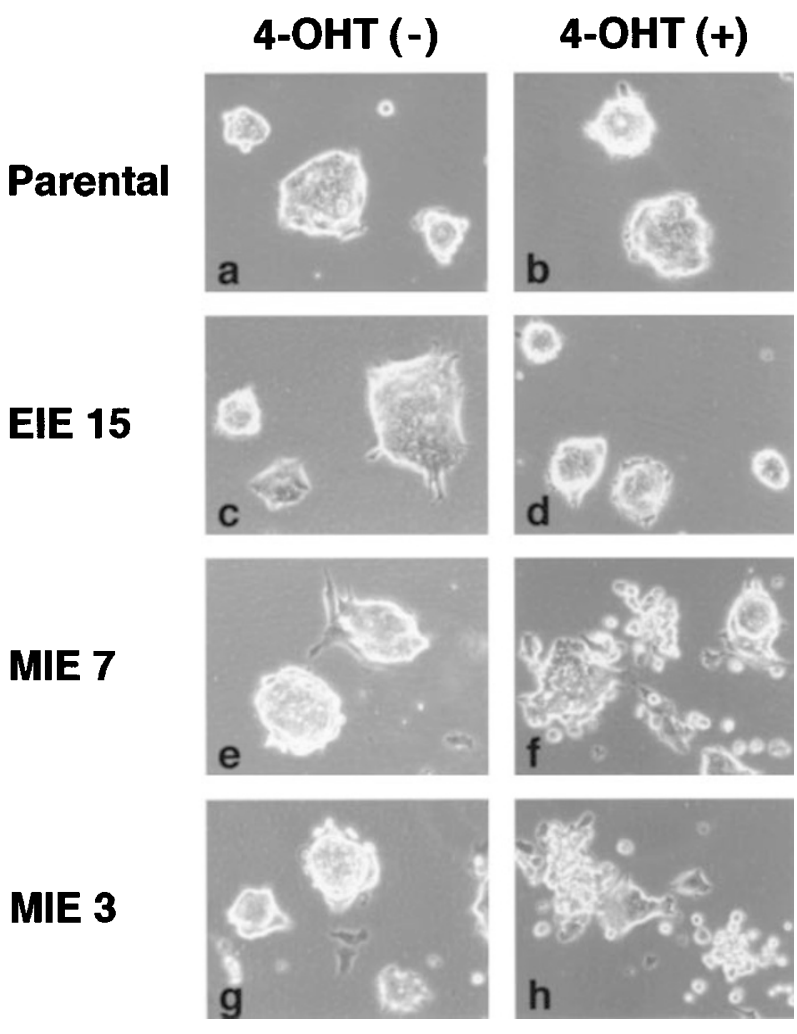

Figure 5 Inhibition of B-Myb activity produces morphological changes. Parental ES cells $(\mathrm{a}, \mathrm{b})$ and clones EIE15 (c,d), MIE7 $(\mathrm{e}, \mathrm{f})$, and MIE3 (g,h) were cultured in the absence (a,c,e,g) and presence $(\mathrm{b}, \mathrm{d}, \mathrm{f}, \mathrm{h})$ of $10^{-7}$ M 4-OHT for $24 \mathrm{~h}$. Detached or loosely attached single ES cells are seen only in 4-OHT(+) MIE clones

(Figure 8b,f). Since one of the most important cell adhesion molecules responsible for the initial phase of EB formation is E-cadherin, surface expression of Ecadherin on the cells detached from gelatin-coated dishes by 4-OHT was examined. As shown in Figure $7 \mathrm{~b}$, the level of E-cadherin expression was significantly reduced in the non-adherent fraction of MIE cells. However, Northern blot hybridization revealed that the E-cadherin mRNA level was not decreased in these cells (data not shown).

\section{Discussion}

We used MERT, an inducible version of dominant interfering Myb proteins, to investigate the function of B-Myb in ES cells. Two phenomena were observed when Myb transactivation activity was interfered with in ES cells. One was cell-cycle arrest at $G_{1}$ phase, with a subsequent reduction in cell number. Cell-cycle arrest was as expected, since it occurs with the ectopic expression of B-Myb (Sala and Calabretta, 1992; Sala et al., 1996) or the introduction of antisense $\mathrm{B}-\mathrm{Myb}$ (Arsura et al., 1992). Unlike hematopoietic cells (Frampton et al., 1996; Taylor et al., 1996), however, interfering with Myb function did not cause apoptotic cell death. The other noticeable, unexpected feature was the alteration of cell adhesion activity. This defective cell adhesion was caused by abnormalities of both cell-extracellular matrix adhesion and cell-cell adhesion, specifically via reduced cell surface expression of $\beta 1$ integrin and E-cadherin, respectively. However, the levels of $\beta 1$ integrin and E-cadherin mRNA expression were not altered by the inhibition of B-Myb.

Mutant mice lacking c-Myb show severe impairment of definitive hematopoiesis, probably due to some defects in hematopoietic stem or progenitor cells (Mucenski et al., 1991). A-Myb-deficient males have a block in spermatogenesis and subsequent infertility (Toscani et al., 1997). Moreover, in female mice, there is underdevelopment of the breast epithelial compart- 

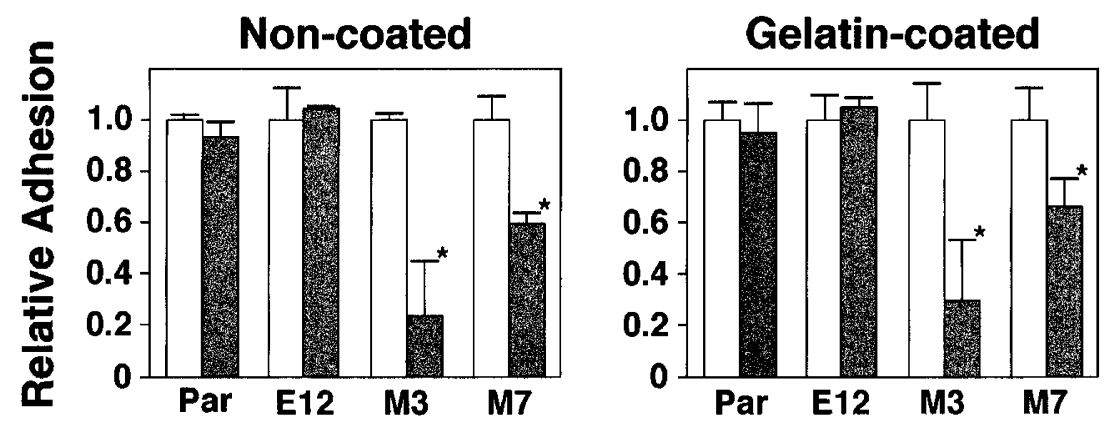

B

Parental

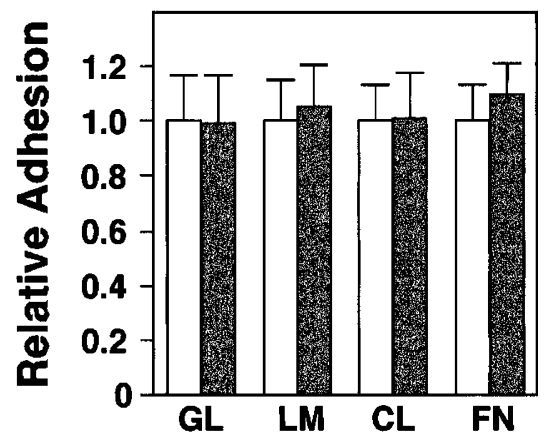

EIE 12

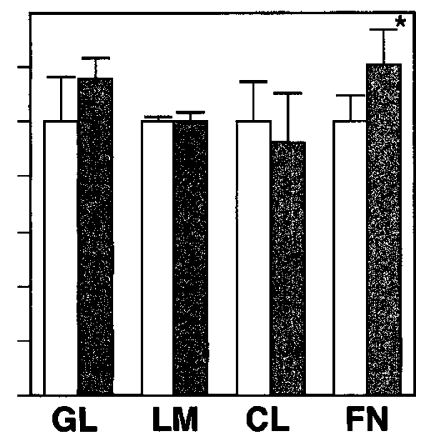

MIE 3

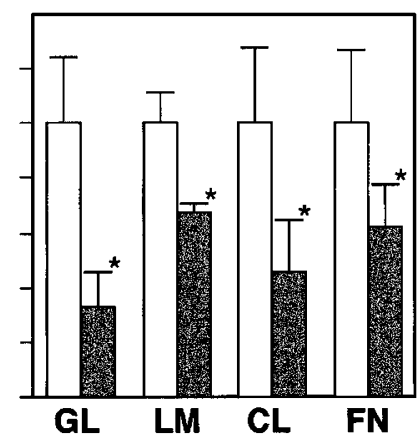

Figure 6 Inhibiting B-Myb influences plating efficiency and cell attachment activity. (a) The plating efficiency of parental ES cells (par) and clones EIE12 (E12), MIE3 (M3), and MIE7 (M7) was analysed in the presence (gray bars) or absence (open bars) of 4OHT. The cells were cultured on non-coated and gelatin-coated dishes for 3 days. Data are shown as the ratio of colonies in the presence and absence of $10^{-7} \mathrm{M} 4-\mathrm{OHT}$ and are the mean \pm standard deviation of four samples. Statistically significant differences $(P<0.05$ by Student's $t$-test) are marked with an asterisk. (b) Cell attachment activity of parental ES cells and clones EIE12 and MIE3 was analysed after culturing for $15 \mathrm{~h}$ in the presence (gray bars) or absence (open bars) of 4-OHT. Extracellular matrix proteins are shown as the following: GL, gelatin; LM, laminin; CL, collagen type IV; FN, fibronectin. Data are shown as the ratio of attached cells in the presence and absence of $10^{-7} \mathrm{M} 4-\mathrm{OHT}$, and are the mean \pm standard deviation of four samples. Statistically significant differences $(P<0.05$ by Student's $t$-test $)$ are marked with an asterisk

ment of the mammary gland following pregnancy. These findings suggest the attractive hypothesis that Myb family proteins play important roles during cell differentiation, especially in the maintenance or differentiation of immature progenitor or stem cells. Evidence from $m y b$-related genes in plants reinforces this notion. Glabra 1 of Arabidopsis thaliana encodes a Myb-related protein found at the top of the trichome pathway (Oppenheimer et al., 1991). Trichomes are branched, hair-like projections that arise from a single cell in the epidermal layer. Glabra 1 is required for both initiation and maintenance of cell fate. However, in ES cells, abrogation of B-Myb function did not alter the differentiation status of the cells at all (data not shown).

Another important role of Myb protein activity is the inhibition of apoptosis. Blocking $\mathrm{c}-\mathrm{Myb}$ function causes apoptotic cell death in mouse $\mathrm{T}$ cells (Taylor et al., 1996) and switching off a Myb-Ets fusion protein in chicken myeloblasts causes apoptosis (Frampton et al., 1996). However, loss of c-Myb protein activity does not necessarily induce apoptosis in all hematopoietic cells. When a dominant negative Myb protein is switched on in mouse erythroleukemia cells, the cells do not die, but arrest in $G_{1}$ phase instead and differentiate (Weston, 1998). Moreover, when a MybEts fusion protein is turned off in chicken myeloiderythroid progenitors, no death is observed, but cells differentiate into thrombocytes (Frampton et al., 1995). Unlike all these cases, only $\mathrm{G}_{1}$ arrest was observed when B-Myb function was repressed in ES cells, but neither apoptosis nor differentiation occurred. This dissociation of $G_{1}$ arrest and the other phenomena is attributable to differences in the functions of $\mathrm{c}-\mathrm{Myb}$ and $\mathrm{B}-\mathrm{Myb}$ or differences in the cell types used.

The most notable abnormality induced by switching on MERT was the change in cell adhesion properties that resulted in the detachment of ES cells and the failure of EB formation. The failure of cell adhesion could be accounted for by defects in cell-extracellular matrix attachment and cell-cell adhesion, which are presumably caused by the defective surface expression of $\beta 1$ integrin and E-cadherin, respectively. It is possible that this failure is a secondary event following cell cycle arrest in $\mathrm{G}_{1}-\mathrm{S}$ transition, since cell adhesion and cell proliferation events are closely related (Giancotti and Ruoslahti, 1999; Ginsberg et al., 1992). Cell-cell interaction and integrin-mediated cell 
A

\section{$\beta-1$ integrin}

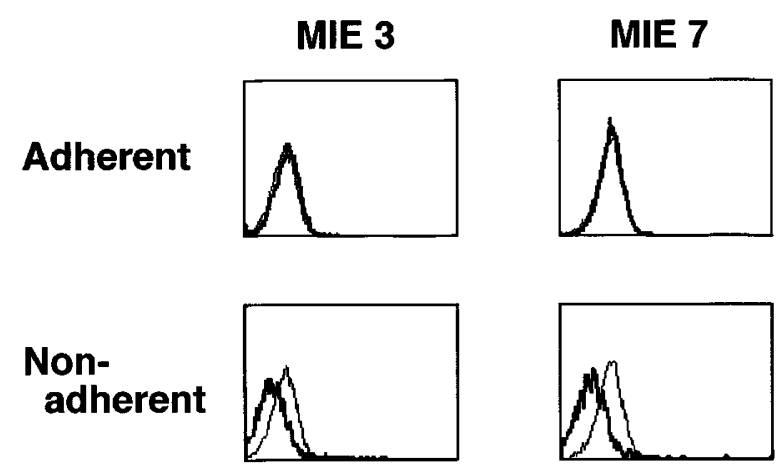

B

E-cadherin

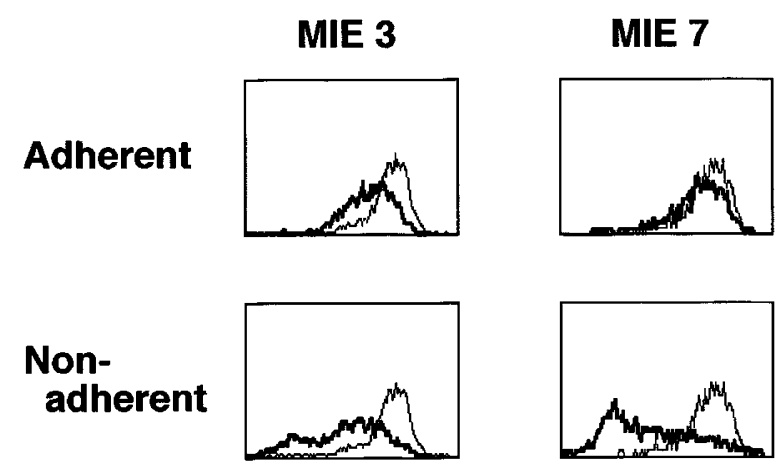

Figure 7 Expression of $\beta$-1 integrin and E-cadherin on adherent and non-adherent cell fractions of MIE clones after inhibiting BMyb. Surface expression of $\beta$-1 integrin (a) and E-cadherin (b) on adherent and non-adherent cells $48 \mathrm{~h}$ after adding 4-OHT. Bold and thin lines show the expression of the cells cultured with and without $10^{-7} \mathrm{M} 4-\mathrm{OHT}$, respectively

adhesion to the extracellular matrix play regulatory roles in cell cycle progression (Levenberg et al., 1999; Manabe et al., 1999; Zhao et al., 1998). To the contrary, certain cell-cycle-related molecules, such as cyclin $\mathrm{C}$ and cdk6, control cell adhesion (Fahraeus and Lane, 1999; Liu et al., 1998). Although significant cell cycle arrest after switching on MERT was observed as early as $18 \mathrm{~h}$ after the addition of 4-OHT (data not shown), the reduction in cell adhesion activity was detected around $15 \mathrm{~h}$. This time course suggests that the defects in the cell cycle and cell adhesion occurred almost simultaneously or that the latter began a little earlier, which implies that the defect in cell adhesion was not a secondary event of the defect in the cell cycle. To examine this interpretation further, we analysed ES cells that were arrested in $G_{1}$ phase by mimosine, a cell cycle-synchronization agent (Krude, 1999). Although mimosine caused $\sim 50 \%$ of the ES cells to arrest as $G_{1}$ cells, which is 2 -3-fold higher than in untreated ES cells (data not shown), no defective cell adhesion was observed as following. The proportion of non-adherent ES cells per total ES cells was $0.32 \pm 0.07 \%$ (mean \pm standard deviation of triplicated samples) under normal culture condition. The proportion was not significantly altered by the addition of mimosine $(0.48 \pm 0.11 \%, P$ value $>0.2$ by Student's $t$-test). Taken together, the defective cell adhesion is not a consequence of the cell-cycle arrest. Since the cell cycle block is primarily caused by the inhibition of B-Myb function as discussed above, the abnormalities in cell cycle and cell adhesion are independent events caused by the activated MERT.

As shown in Figure 7a, there was virtually no surface expression of $\beta 1$ integrin on the detached ES cells. The defective cell matrix attachment to collagen, fibronectin, and laminin can be explained by the defective $\beta 1$ integrin expression, because treatment with blocking antibodies against cell-surface $\beta_{1}$ integrin (kindly provided by $\operatorname{Dr}$ Yagita) similarly reduced adhesion of ES cells to these substrates (data not shown). $\beta 1$ integrin targeted ES cells show similar cell adhesion defects, but no detachment of those cells was observed (Fassler et al., 1995). This discrepancy is probably due to the defective expression of E-cadherin in addition to absent $\beta 1$ integrin expression on the surface of MERT-activated ES cells. Similarly, the profound defects in the production of EB can be explained by the defective E-cadherin expression. The defects in $\beta 1$ integrin expression might contribute to the poor EB formation to some extent, but the effect of $\beta 1$ integrin should not be crucial, since $\beta 1$ integrin null embryos develop normally to the blastocyst stage (Fassler and Meyer, 1995; Fassler et al., 1995) and cell aggregation for EB formation is only slightly retarded.

We thought that the expression of both $\beta 1$ integrin and E-cadherin mRNA might be reduced in the detached ES cells and examined this possibility. However, no significant reduction was observed by RT - PCR or Northern blot analysis. General reduction of cell surface molecules by switching on MERT is unlikely, since significant percentages of the cells show high expression of E-cadherin, even the non-adherent fraction in Figure 7b. This finding suggests that interference with $\mathrm{Myb}$ function might compromise translation or subsequent processing of the $\beta 1$ integrin and E-cadherin proteins, perhaps affecting vesicular transport towards the cell membrane or post-translational modifications, such as glycosylation (Bellis et al., 1999), localization, and stabilization at focal adhesions. The identification of the B-Myb target gene(s) involved in the $\beta 1$ integrin and E-cadherin processing pathways remains a subject of future investigation. There was a tendency that the EGFP expression in non-adherent fraction was higher than that in adherent fraction, however, it was not in an 'all-or-none' fashion. Other cell adhesion related molecules might be affected posttranscriptionally by some indirect functions of activated MERT and those molecules would play some roles on the cell adhesion. 

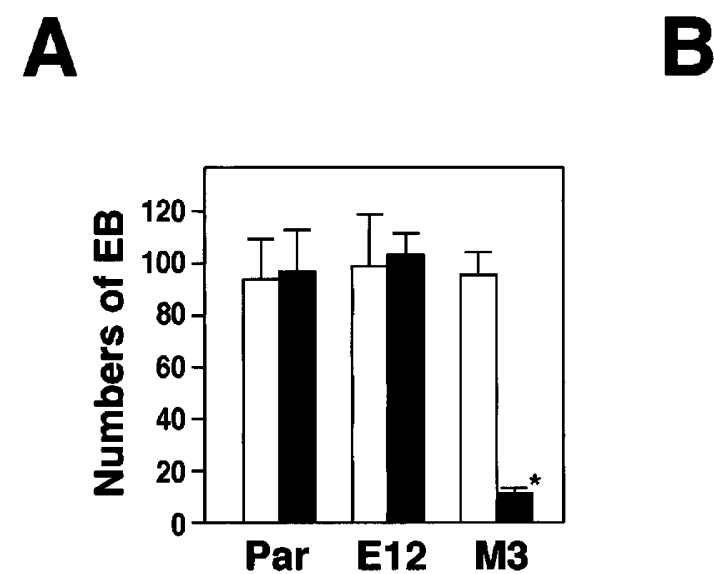

\section{4-OHT (-) 4-OHT (+)}

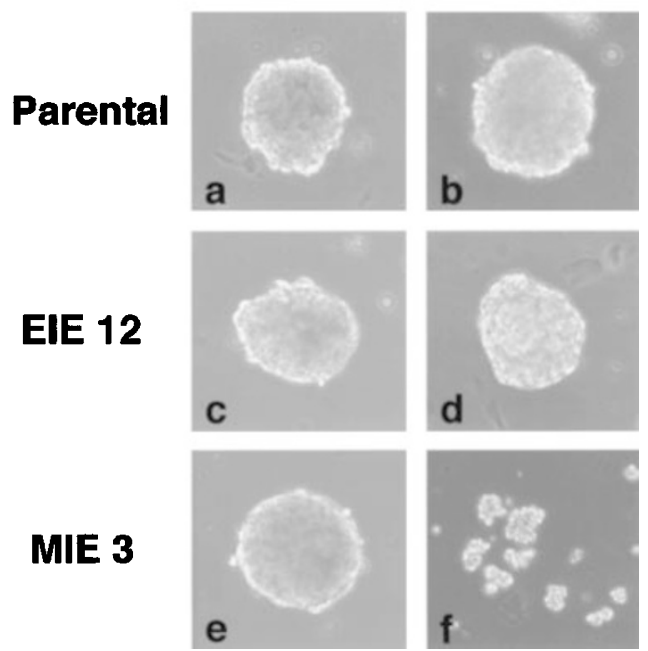

Figure 8 Embryoid body formation and its morphology. (a) The numbers of embryoid bodies produced from parental ES cells (par) and clones EIE12 (E12) and MIE3 (M3) are shown as the mean \pm standard deviation of four samples. The numbers of EB in the absence and presence of 4-OHT are shown as open and gray bars, respectively. A drastic reduction of EB formation was observed by inhibiting B-Myb. Statistically significant difference $(P<0.05$ by Student's $t$-test $)$ is marked with an asterisk. (b) Photographs of cell clusters under EB-forming conditions. Parental ES cells (a,b), clone EIE12 (c,d), and clone MIE3 (e,f) were cultured under EB-forming conditions in the absence or presence of 4-OHT. Significant numbers of cell clusters that did not form EB were observed in MIE3 clones in the presence of 4-OHT (f)

Recently, B-Myb-deficient mice were produced by gene targeting and the phenotype was reported. The heterozygous mutants were healthy, but the homozygous mutants died at an early stage of development, around embryonic day $4.5 \sim 6.5$. Although $\mathrm{B}-\mathrm{Myb}^{-1-}$ blastocysts were indistinguishable from $\mathrm{B}-\mathrm{Myb}^{+/-}$or

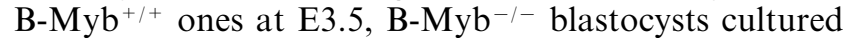
in vitro for 5 days showed severely impaired proliferation of the inner cell mass. In addition, B-Myb-1- ES cell lines could not be obtained. In $\mathrm{B}-\mathrm{Myb}^{-/-}$mice, trophoectoderm cell development and trophoblast differentiation were observed in spite of the subsequent rapid abnormal growth of the blastocysts, which is very similar to the phenotype of $\beta 1$ integrin null mice. As shown in Figure 7, ES cells with activated MERT showed virtually no $\beta 1$ integrin expression, but significant E-cadherin expression. The impaired $\mathrm{G}_{1} / \mathrm{S}$ transition of $\mathrm{B}-\mathrm{Myb}^{-1-}$ embryos is surely one explanation for the early lethality of $\mathrm{B}-\mathrm{Myb}^{-/-}$embryos. Taken together, however, we believe that abnormalities in cell adhesion are another, and probably more important, cause of the defects in B-Myb ${ }^{-/-}$embryos.

Concerning cell adhesion molecules regulated by Myb proteins, the $\alpha 4$ integrin gene is transcriptionally regulated by c-Myb in hematopoietic cells. A heterodimeric $\alpha 4 \beta 1$ integrin (VLA4) is an essential cell adhesion molecule on hematopoietic cells. Our results show that B-Myb, another Myb family member, regulates cell adhesion molecules, including $\beta 1$ integrin and E-cadherin, although the regulating mechanisms remain to be elucidated. In conclusion, it is certain that Myb family genes play important roles in cell adhesion, as well as in cell proliferation and cell differentiation.

\section{Materials and methods}

\section{Plasmid construction}

pMCEF-MERT-IE and pMCEF-ERT-IE were constructed as follows. pCMV-IRES-EGFP (a kind gift of Dr A Kume, Jichi Medical School, Tochigi, Japan) (Kume et al., 1999), which contains an XhoI site and a BamHI site at the $5^{\prime}$ and $3^{\prime}$ ends of the IRES-EGFP fragment, respectively, was digested with $X h o I$, and blunt-ended with Klenow polymerase. This fragment was ligated with BamHI linkers, digested with BamHI, and cloned into the downstream BamHI site of pMCEF-MERT and pMCEF-ERT (a kind gift of Dr K Weston (Taylor et al., 1996)) to give rise to pMCEF-MERTIE and pMCEF-ERT-IE, respectively. All ligated portions were confirmed by DNA sequencing.

\section{Cell culture}

D3 mouse ES cells were maintained on embryonic fibroblast feeder cells in the presence of leukemia-inhibitory factor following standard methods (Joyner, 1993). To obtain stable transformants of ES cells, $8 \times 10^{6}$ cells were electroporated with $20 \mu \mathrm{g}$ of the linearized plasmid DNA at $230 \mathrm{~V}$ and $500 \mu \mathrm{F}$ using a Bio-Rad gene pulser and then selected in the presence of $250 \mu \mathrm{g} / \mathrm{ml} \mathrm{G} 418$ (Sigma, St Louis, MO, USA). To activate the MERT and ERT proteins, cells were cultured in the presence of $10^{-7} \mathrm{M}$ 4-OHT (Sigma) in most experiments except luciferase assay. For luciferase analysis, $2 \mu \mathrm{g}$ of 6MBS-Luc plasmids (Takahashi et al., 2000) was transfected with Lipofectamine 2000 (Gibco BRL, Rockville, $\mathrm{MD}$, USA) in 6 well plates. $5 \times 10^{-8} \mathrm{M} 4-\mathrm{OHT}$ was added $24 \mathrm{~h}$ after the transfection and luciferase activity was analysed $48 \mathrm{~h}$ after the transfection. In most experiments, feeder cells were removed by incubation on $0.1 \%$ gelatincoated dishes for $30 \mathrm{~min}$ and then ES cells were harvested as non-adherent cells and analysed. For cell growth analysis, ES 
cells were trypsinized and the numbers of viable cells were counted by Trypan blue exclusion.

\section{FACS and cell cycle analyses}

To analyse EGFP expression, single-cell suspensions obtained by trypsinization were washed twice with PBS, stained with $1 \mu \mathrm{g} / \mathrm{ml}$ propidium iodide (PI), and analysed using FACSCalibur (Becton Dickinson, Franklin Lakes, NJ, USA). PInegative cells were examined for FL1 fluorescence intensity to detect EGFP. Single-cell suspensions were washed twice with PBS, and cells were sorted into EGFP-positive and EGFPnegative cells using FACSVantage (Becton Dickinson). For cell cycle analysis, sorted cells were centrifuged and resuspended in PBS containing $0.1 \%$ Triton X-100, $0.5 \mathrm{mg} / \mathrm{ml}$ RNase, and $25 \mu \mathrm{g} / \mathrm{ml}$ PI. The samples were incubated for at least $15 \mathrm{~min}$ in the dark and analysed using FACSCalibur (Becton Dickinson). The cell cycle composition was analysed using the program ModFit LT.

\section{Immunostaining}

For immunostaining, cultured ES cells were harvested with cell dissociation buffer (Gibco BRL) and washed twice with PBS. Cells were incubated with $5 \mu \mathrm{g} / \mathrm{ml}$ rat anti-mouse CD29 ( $\beta 1$ integrin) monoclonal Ab (PharMingen, San Diego, CA, USA) or $10 \mu \mathrm{g} / \mathrm{ml}$ rat anti-mouse E-cadherin monoclonal $\mathrm{Ab}$ (Takara Biomedicals, Kusatsu, Japan). After washing, cells were incubated with $20 \mu \mathrm{g} / \mathrm{ml}$ mouse anti-rat phycoerythrinconjugated monoclonal Ab (PharMingen, San Diego, CA, USA), washed, and analysed using FACSCalibur (Becton Dickinson).

\section{Cell adhesion assay}

The cell adhesion assay was carried out essentially as described previously (Priddle et al., 1998). 96-well tissue culture plates (Nunc, Roskilde, Denmark) were coated with $0.1 \%$ gelatin, $50 \mu \mathrm{g} / \mathrm{ml}$ mouse laminin (Biomedical Technologies Inc., Stoughton, MA, USA), $10 \mu \mathrm{g} / \mathrm{ml}$ mouse type IV collagen (Gibco BRL), or $10 \mu \mathrm{g} / \mathrm{ml}$ human plasma fibronec-

\section{References}

Arsura M, Introna M, Passerini F, Mantovani A and Golay J. (1992). Blood, 79, 2708-2716.

Badiani P, Corbella P, Kioussis D, Marvel J and Weston K. (1994). Genes Dev., 8, 770-782.

Bellis SL, Newman E and Friedman EA. (1999). J. Cell. Physiol., 181, 33-44.

Bradley A, Evans M, Kaufman MH and Robertson E. (1984). Nature, 309, 255-256.

Fahraeus R and Lane DP. (1999). EMBO J., 18, 2106-2118.

Fassler R and Meyer M. (1995). Genes Dev., 9, 1896-1908.

Fassler R, Pfaff M, Murphy J, Noegel AA, Johansson S, Timpl R and Albrecht R. (1995). J. Cell. Biol., 128, 979988.

Frampton J, McNagny K, Sieweke M, Philip A, Smith G and Graf T. (1995). EMBO J., 14, 2866-2875.

Frampton J, Ramqvist T and Graf T. (1996). Genes Dev., 10, $2720-2731$.

Giancotti FG and Ruoslahti E. (1999). Science, 285, $1028-$ 1032.

Ginsberg MH, Du X and Plow EF. (1992). Curr. Opin. Cell. Biol., 4, $766-771$.

Joyner AL. (1993). IRL Press, 142, $1121-1133$. tin (Gibco BRL) overnight at $4^{\circ} \mathrm{C}$, and then blocked with $2 \%$ BSA. ES cells were trypsinized. The trypsin was neutralized by the addition of FCS-containing medium, and the cells were resuspended $\left(8 \times 10^{6}\right.$ cells $\left./ \mathrm{ml}\right)$ in serum-free medium. Then, $100 \mu \mathrm{l}$ of cell suspension was added to each well and the cells were allowed to attach for $1 \mathrm{~h}$ at $37^{\circ} \mathrm{C}$. Nonadherent cells were removed by washing three times with PBS, and the attached cells were fixed with $10 \%$ formaldehyde for $30 \mathrm{~min}$, then stained with $1 \%$ toluidine blue for $1 \mathrm{~h}$. The wells were washed extensively with water and dried in air. Then, the dye was extracted with $2 \%$ SDS. The absorbance at $620 \mathrm{~nm}$ was measured with a microtiter plate reader. The assays were carried out in four wells and the experiments were repeated more than twice.

\section{Embryoid body formation}

Embryoid body formation was carried out essentially the same as described (Wiles, 1993). ES cells were trypsinized, suspended in LIF-free ES cell medium, and feeder cells were removed by incubating the cells on gelatin-coated dishes for $30 \mathrm{~min}$. Non-adherent cells were harvested and re-suspended in $\alpha$-MEM containing $1 \%$ methylcellulose, $15 \%$ fetal calf serum, and $1 \times 10^{-4} \mathrm{M} \beta$-mercaptoethanol. Cells were plated on $35 \mathrm{~mm}$ suspension culture dishes (Corning, NY, NY, USA) at a density of $1 \times 10^{4}$ cells/dish. Two days after initiating the culture, 4-OHT was added at a final concentration of $1 \times 10^{-7} \mathrm{M}$. Morphological examination and embryoid body counts were done 6 days after initiating the culture.

\section{Acknowledgments}

We thank Drs K Weston, H Yagita, S Ishii and A Kume for gifting us various reagents and useful discussion. This work was supported in part by grants from the Ministry of Education, Science, Sports and Culture, Japanese Society for Promotion of Sciences (JSPS-RFTF98L01101), and the Cell Science Research Foundation.

Krude T. (1999). Exp. Cell. Res., 247, $148-159$.

Kume A, Hashiyama M, Suda T and Ozawa K. (1999). Stem Cells, 17, 226-232.

Larue L, Antos C, Butz S, Huber O, Delmas V, Dominis M and R K. (1996). Development, 122, 3185-3194.

Levenberg S, Yarden A, Kam Z and Geiger B. (1999). Oncogene, 18, 869-876.

Lipsick JS. (1996). Oncogene, 13, 223 - 235.

Littlewood TD, Hancock DC, Danielian PS, Parker MG and Evan GI. (1995). Nucleic Acids Res., 23, 1686-1690.

Liu ZJ, Tanaka Y, Mine S, Morinobu A, Yagita H, Okumura $\mathrm{K}$, Taniguchi T, Yamamura $\mathrm{H}$ and Minami $\mathrm{Y}$. (1998). Blood, 92, 4700-4711.

Lyon JJ and Watson RJ. (1996). Gene, 182, 123-128.

Manabe R, Oh-e N and Sekiguchi K. (1999). J. Biol. Chem. 274, 5919-5924.

Martin GR. (1981). Proc. Natl. Acad. Sci. USA, 78, $7634-$ 7638.

Mucenski ML, McLain K, Kier AB, Swerdlow SH, Schreiner CM, Miller TA, Pietryga DW, Scott WJJ and Potter SS. (1991). Cell, 65, 677-689.

Ness SA. (1999). Oncogene, 18, 3039 - 3046. 
Nomura N, Takahashi M, Matsui M, Ishii S, Date T, Sasamoto S and Ishizaki R. (1988). Nucleic Acids Res., 16, $11075-11089$.

Oppenheimer DG, Herman PL, Sivakumaran S, Esch J and Marks MD. (1991). Cell, 67, 483-493.

Priddle H, Hemmings L, Monkley S, Woods A, Patel B, Sutton D, Dunn GA, Zicha D and Critchley DR. (1998). J. Cell. Biol., 142, $1121-1133$.

Riethmacher D, Brinkmann V and Birchmeier C. (1995). Proc. Natl. Acad. Sci. USA, 92, 855-859.

Saitou M, Sugai S, Tanaka T, Shimouchi K, Fuchs E, Narumiya S and Kakizuka A. (1995). Nature, 374, 159 162.

Sala A and Calabretta B. (1992). Proc. Natl. Acad. Sci. USA, 89, 10415 - 10419 .

Sala A, Casella I, Bellon T, Calabretta B, Watson RJ and Peschle C. (1996). J. Biol. Chem., 271, 9363 - 9367.

Sitzmann J, Noben-Trauth K, Kamano H and Klempnauer KH. (1996). Oncogene, 12, 1889-1894.
Takahashi T, Suwabe N, Dai P, Yamamoto M, Ishii S and Nakano T. (2000). Oncogene, 19, 134-140.

Tanaka Y, Patestos NP, Maekawa T and Ishii S. (1999). J. Biol. Chem., 274, 28067-28070.

Taylor D, Badiani P and Weston K. (1996). Genes Dev., 10, $2732-2744$.

Toscani A, Mettus RV, Coupland R, Simpkins H, Litvin J, Orth J, Hatton KS and Reddy EP. (1997). Nature, 386, $713-717$.

Westin EH, Gallo RC, Arya SK, Eva A, Souza LM, Baluda MA, Aaronson SA and Wong-Staal F. (1982). Proc. Natl. Acad. Sci. USA, 79, 2194-2198.

Weston K. (1998). Curr. Opin. Genet. Dev., 8, 76-81.

White JR and Weston K. (2000). Oncogene, 19, 1196-1205.

Wiles MV. (1993). Methods Enzymol., 225, 900-918.

Zhao JH, Reiske H and Guan JL. (1998). J. Cell. Biol., 143, $1997-2008$ 